\title{
Robust Control of the Knee Joint Angle of Paraplegic Patients considering Norm-Bounded Uncertainties
}

\author{
Nilson Moutinho dos Santos, ${ }^{1}$ Ruberlei Gaino, ${ }^{2}$ Márcio Roberto Covacic, ${ }^{2}$ \\ Marcelo Carvalho Minhoto Teixeira, ${ }^{3}$ Aparecido Augusto de Carvalho, ${ }^{3}$ Edvaldo Assunção, ${ }^{3}$ \\ Rodrigo Cardim, ${ }^{3}$ and Marcelo Augusto Assunção Sanches ${ }^{3}$ \\ ${ }^{1}$ Engenharia Elétrica, Área de Exatas, Faculdade Ingá, Rodovia PR 317, No. 6114, 87035-510 Maringá, PR, Brazil \\ ${ }^{2}$ Department of Electrical Engineering, Urban Planning and Technology Center, State University of Londrina, \\ Rodovia Celso Garcia Cid PR 445, Km 380, 86057-970 Londrina, PR, Brazil \\ ${ }^{3}$ Department of Electrical Engineering, Universidade Estadual Paulista (UNESP), Campus de Ilha Solteira, \\ 15385-000 Ilha Solteira, SP, Brazil \\ Correspondence should be addressed to Ruberlei Gaino; rgaino@uel.br
}

Received 4 September 2014; Revised 17 December 2014; Accepted 18 December 2014

Academic Editor: John Gunnar Carlsson

Copyright (C) 2015 Nilson Moutinho dos Santos et al. This is an open access article distributed under the Creative Commons Attribution License, which permits unrestricted use, distribution, and reproduction in any medium, provided the original work is properly cited.

A proposal for the knee position control design of paraplegic patients with functional electrical stimulation (FES) using control systems and considering norm-bounded uncertainties is presented. A state-space representation of the knee joint model of the paraplegic patient with its nonlinearity is also demonstrated. The use of linear matrix inequalities (LMIs) in control systems with norm-bounded uncertainties for asymptotic stability is analyzed. The model was simulated in the Matlab environment. The matrix $K$ of state space feedback was obtained through LMIs.

\section{Introduction}

The application of electrical stimulation in a person's muscle, more particularly in his motor neurons, causes involuntary contraction of this muscle [1].

In order to obtain a muscle contraction it is necessary that the amplitude (or intensity) and duration of the electrical stimulus are inside specific bounds. Then an action potential (AP) is generated and propagates in both directions of the nerve fiber. Complex mechanisms of electrochemical stimuli occur in the neuromuscular structure causing the process of excitation-contraction coupling responsible for the movement of the leg [2].

The modulation of the force by a number of muscle fibers recruited and the speed of fiber recruitment depends on several parameters. Some of these parameters include the proximity of the nerve fiber and the electrode, the electrode diameter, and the variation of the number of active states of the fibers due the variation of the amplitude or pulse duration. As can be seen in Figure 1, the degree of muscle activation, $\alpha$, is a nonlinear function. It depends on the duration of the stimulus, $d[3]$.

Muscle is a highly complex nonlinear system, capable of producing the same output for a variety of inputs. A property exploited by physiologically activated muscle is its effort to minimize fatigue [4].

Several researchers have used FES to restore some motion activities of persons with injured spinal cord [5]. However, FES is not yet a regular clinical method, because the amount of effort involved in using actual stimulation systems still outweighs the functional benefits they provide.

One serious problem when using FES is that artificially activated muscles fatigue at a faster rate than those activated by the natural physiological processes. Due to these problems, a considerable effort has been directed toward developing FES systems based on closed loop control. 


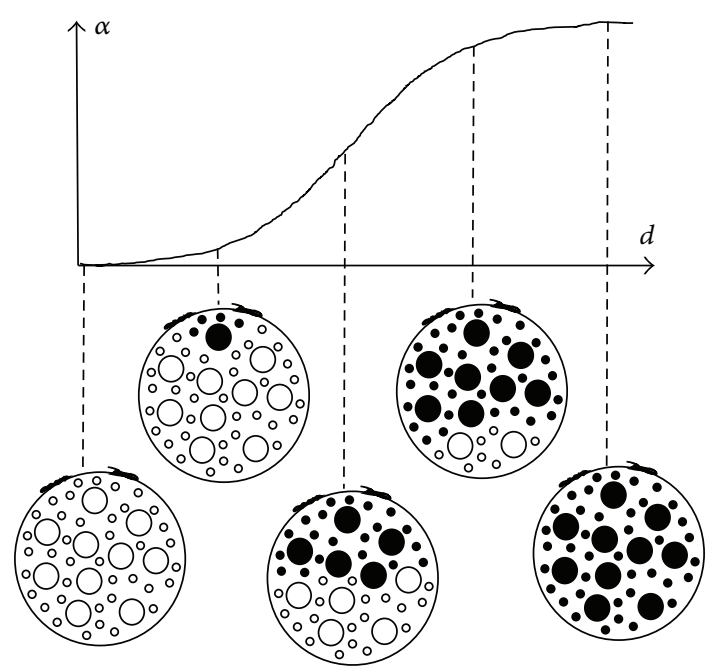

FIGURE 1: Fibers recruitment curve (the black circles are activated fibers) [3].

Ferrarin and Pedotti developed a dynamic model for the relationship between electrical stimulus and joint torque [5]. In their paper, the dynamics of the lower limb were represented by a nonlinear second-order model, which took into account the gravitational and inertial characteristics of the anatomical segment as well as the damping and stiffness properties of the knee joint.

Considering that when the quadriceps is electrically stimulated its response is nonlinear, Teixeira et al. [7] proposed a nonlinear controller with the aim of controlling the position of the leg of a paraplegic patient [7]. The authors designed a controller to vary the knee joint angle using Takagy-Sugeno fuzzy models. When electrical stimulation is applied to the quadriceps of a patient, using the controller, the knee joint angle can be varied from $0^{\circ}$ to $30^{\circ}$. The authors considered the leg mathematical model proposed by [5], and they showed that, for the conditions considered in their experiments, a simple one-pole transfer function was able to model the relationship between stimulus pulse width and active muscle torque [8].

This paper presents a proposal for the leg position control design of paraplegic patients with FES using control systems with uncertainties bounded in norm and a feedback signal obtained from an electrogoniometer which is the most commonly used sensor for measuring the knee joint angle.

As mentioned in [9] "Complex control systems have been recently employed to control the communications among computers, controllers, and sensors due to the enlarging scale of control systems in nowadays applications." Nowadays, it is a very important issue for dynamic systems design.

\section{Nonlinear Knee Joint Model}

As observed by Gaino et al. in [6], the FES systems based on open-loop control have some shortcomings related to the lack of sensitivity to both external disturbances and changes in internal parameters. On the other hand, FES systems

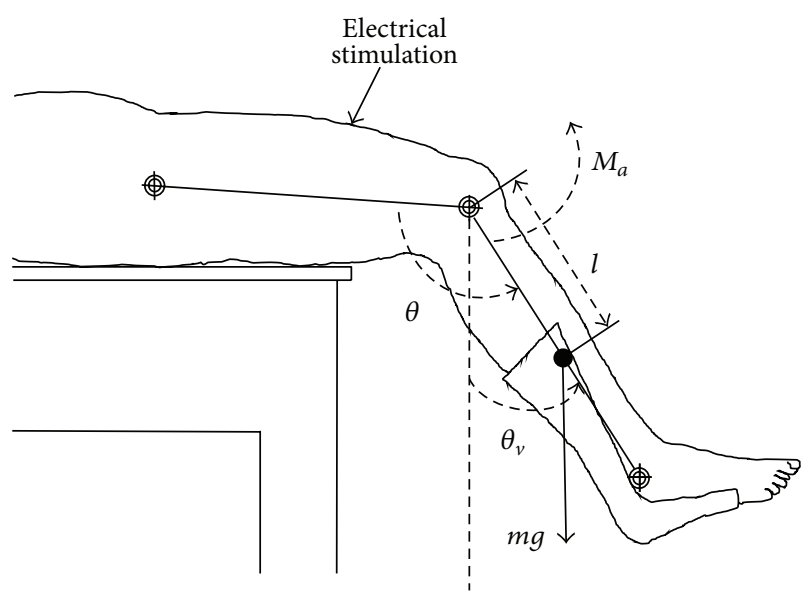

FIGURE 2: Schematic representation of the patient knee joint plant [6].

based on closed loop control allow real-time measurement of the motion produced by means of sensors and provide a stimulation pattern with the appropriate modulation [5]. This allows the optimization of the neurostimulator pulse width with consequent reduction of muscle fatigue. Furthermore, Gaino et al. demonstrated in [6] that the feedback signal related to the angle of the knee joint may be obtained by using electrogoniometers.

The chosen plant is the knee joint, and the open kinematic chain is made of two rigid segments: the thigh and shankfoot complex [5], illustrated in Figure 2. It allows us to study the relationship between the major parameters of input stimulation and the torque of the knee joint. In other words, the pulse width with the output represented by the torque of the active knee joint produced by muscles is stimulated under nonisometric conditions [10]. The ankle was fixed using a plastic ankle foot orthosis (AFO), reducing the number of plant's degrees of freedom, causing the length of biarticular muscles to depend only on the position of the knee joint. The thigh was fixed to the support table so that only the dynamics of shank-foot and flexion-extension knee movements were considered. This model was originally proposed in [5].

The positioning of the knee at a desired angle $\theta$ between shank and thigh in the sagittal plane is obtained by FES stimulation of the quadriceps muscles $[5,6]$. The angle between the shank and the vertical axis in the sagittal plane is $\theta_{v}$ and the active torque produced by FES in the quadriceps is $M_{a}$ [12].

As in $[2,12]$, the system's point of interest is $\theta_{v 0}=30^{\circ}$, and the operating point of the system is not the origin. Thus, according to the stability theory of Lyapunov, it is necessary to make a change of variables to transfer the new operation point to the origin. Thus, the state variables of (1) are given by the following:

(i) $x_{1}(t)=\Delta \theta_{v}=\theta_{v}-\theta_{v 0}$, where $\theta_{v}$ is the angle between the shank and the vertical axis in the sagittal plane;

(ii) $x_{2}=\dot{x}_{1}$, the knee joint angular velocity; 
TABLE 1: Parameter values obtained experimentally in $[5,6,11]$ to the shank-foot complex of a paraplegic, 30 -year-old patient.

\begin{tabular}{|c|c|c|c|}
\hline & Parameter & Value & Unit \\
\hline$J$ & Inertial moment of shank-foot complex & 0.362 & $\mathrm{Kg} \cdot \mathrm{m}^{2}$ \\
\hline$m$ & Mass of shank-foot complex & 4.37 & $\mathrm{Kg}$ \\
\hline$l$ & Distance between knee and the center of the mass of shank-foot complex & 23.8 & $\mathrm{~cm}$ \\
\hline$B$ & Viscous coefficient & 0.27 & $\mathrm{~N} \cdot \mathrm{m} \cdot \mathrm{s} / \mathrm{rad}$ \\
\hline$\lambda$ & Coefficient of exponential term & 41.208 & $\mathrm{~N} \cdot \mathrm{m} / \mathrm{rad}$ \\
\hline$E$ & Coefficient of exponential term & 2.024 & $\operatorname{rad}^{-1}$ \\
\hline$\omega$ & Resting elastic knee angle & 2.918 & $\mathrm{rad}$ \\
\hline$\tau$ & Transfer function coefficient (time constant of the pole) & 0.951 & s \\
\hline G & Transfer function coefficient (static gain) & 42500 & $\mathrm{~N} \cdot \mathrm{m} / \mathrm{s}$ \\
\hline
\end{tabular}

(iii) $x_{3}=\Delta M_{a}=M_{a}-M_{a 0}$, where $M_{a 0}$ is the active torque (on quadriceps muscle of the paraplegic patient) in the operation point.

The plant parameters with their meanings and values were obtained experimentally for the case of one patient in $[5,6]$ and they are shown in Table 1.

The movement of the knee joint resulting from the electrical stimulus applied to the quadriceps is represented by the nonlinear state equation (1), according to Gaino et al. in $[2,12]$ :

$$
\left[\begin{array}{l}
\dot{x}_{1} \\
\dot{x}_{2} \\
\dot{x}_{3}
\end{array}\right]=\left[\begin{array}{ccc}
0 & 1 & 0 \\
\tilde{f}_{21}\left(x_{1}\right) & -\frac{B}{J} & \frac{1}{J} \\
0 & 0 & -\frac{1}{\tau}
\end{array}\right]\left[\begin{array}{l}
x_{1} \\
x_{2} \\
x_{3}
\end{array}\right]+\left[\begin{array}{l}
0 \\
0 \\
\frac{G}{\tau}
\end{array}\right] P_{N} .
$$

The nonlinearity of the mathematical model of the plant comes through the element $a_{21} \rightarrow \widetilde{f}_{21}\left(x_{1}(t)\right)$ of the characteristic matrix of the system $[2,6,11,12]$, which is given by

$$
\begin{aligned}
\widetilde{f}_{21}\left(x_{1}(t)\right)=\frac{1}{J x_{1}} m g l \sin \left(x_{1}(t)+\theta_{v 0}\right)-\frac{1}{J x_{1}} \\
\times\left[\lambda \exp \left(-E\left(x_{1}(t)+\theta_{v 0}+\frac{\pi}{2}\right)\right)\right. \\
\\
\left.\cdot\left(x_{1}(t)+\theta_{v 0}+\frac{\pi}{2}-w\right)+M_{a 0}\right] .
\end{aligned}
$$

As defined in $[2,6,11,12]$, at the operating point of interest, the following values for the variables are found: $\theta_{v}=$ $\theta_{v 0}=30^{\circ}$, and the derivatives $\dot{\theta}_{v}$ and $\ddot{\theta}_{v}$ are null. In this case, the active torque of the knee, $M_{a 0}$, produced by electrical stimulation, is given by

$$
\begin{aligned}
M_{a 0}= & m g l \sin \left(\theta_{v 0}\right) \\
& +\lambda \exp \left(-E\left(\theta_{v 0}+\frac{\pi}{2}\right)\right)\left(\theta_{v 0}+\frac{\pi}{2}-w\right) .
\end{aligned}
$$

Considering the values of the parameters of Table 1 , taking $g=9.8\left(\mathrm{~m} / \mathrm{s}^{2}\right)$ and $\theta_{\nu 0}=\pi / 6$, and substituting in (3) the value of $M_{a 0}=4.6068(\mathrm{~N} \cdot \mathrm{m})$ is obtained. In the case where $\theta_{v 0}=\pi / 3(\mathrm{rad}), M_{a 0}=8.7653(\mathrm{~N} \cdot \mathrm{m})$.

The new input of the system, $P_{N}$, is defined from the system input, $P$, and is known as the pulse width unreferenced $[2,6,11,12]$. It is given by

$$
P_{N}=P-\frac{M_{a 0}}{G} .
$$

Since there will only be movement of the paraplegic's leg if an electrical stimulation pulse is applied to the skin of the thigh, that is, $P>0$, this implies that

$$
P_{N}>-\frac{M_{a 0}}{G}
$$

\section{Robust Control Systems with Norm-Bounded Uncertainties}

In this section the concept of control systems with normbounded uncertainties is presented and its methodology is used to design a control angle of the knee joint angle in paraplegic patients discussed in Section 2.

3.1. Systems Control with Norm-Bounded Uncertainties. Let the plant be represented by

$$
\dot{x}=(A+\delta A) x+(B+\delta B) u,
$$

where the uncertainty matrices are given by

$$
\delta A=L \Delta R_{A}, \quad \delta B=L \Delta R_{B}, \quad \Delta \Delta^{T} \preceq I .
$$

The matrix $\Delta$ is the diagonal matrix of the uncertainties, containing the uncertain parameters normalized on the main diagonal, while the modulus of each is less than or equal to 1. The matrices $R_{A}$ and $R_{B}$ are algebraically determined, so that it suits expressions in (6) for $\delta A$ and $\delta B$ given in (7).

Theorem 1, that follows the ideas of [13], establishes a sufficient condition for the stability of system (6) in open loop, with the uncertain matrices given in (7) and $u=0$, in other words, null input. 
Theorem 1 (see [13]). The plant (6) is stable for any matrices $\delta A$ and $\delta B$ defined in (7) if there exists a matrix $X=X^{T}$ and a real constant $\epsilon$ that satisfy the following conditions:

$$
\begin{gathered}
{\left[\begin{array}{cc}
A X+X A^{T}+\epsilon L L^{T} & X R_{A}^{T} \\
R_{A} X & -\epsilon I
\end{array}\right] \prec 0,} \\
X \succ 0 .
\end{gathered}
$$

Consider, now, the plant (6), with the matrices $\delta A$ and $\delta B$ given in (7) and the control law with states feedback:

$$
u=-K x \text {. }
$$

Thus, considering (6), (7), and the control law (9), the feedback system is defined by

$$
\dot{x}=\left[(A-B K)+L \Delta\left(R_{A}-R_{B} K\right)\right] x .
$$

Theorem 2, that follows the ideas of [13], below corresponds to Theorem 1 but applies to the closed loop system and establishes a sufficient condition for the stability of the feedback system (10), with uncertain matrices given in (7) and input $u=-K x$.

Theorem 2 (see [13]). System (10) is stable for any matrices $\delta A$ and $\delta B$ defined in (7) if there are matrices $X=X^{T}$ and $W$ and a real constant $\epsilon$ which satisfies the following conditions:

$$
\left[\begin{array}{cc}
A X+X A^{T}-B W-W^{T} B^{T}+\epsilon L L^{T} & X R_{A}^{T}-W^{T} R_{B}^{T} \\
R_{A} X-R_{B} W & -\epsilon I
\end{array}\right] \prec 0,
$$

$$
X>0 .
$$

Based on the solution, the matrix $K$ is given by $K=$ $W X^{-1}$.

3.2. Systems Control with Output Restriction. According to Boyd in $[14,15]$, stability analysis and control design problems are likely to be described by LMIs, allowing the introduction of other performance indices in the controller design, for example, the specification of the transient response by the decay rate and constraint specifications on the amplitude of control signals and outputs.

A system that offers robust performance should be able to maintain its performance even in the presence of perturbations and disturbances, which are called uncertainties.

Considering a known initial condition $x(0)$ and the LMIs (14), the output $y(t)=C x(t)$ can be subjected to the constraint (13), for all time $t \geq 0$ :

$$
\max \|y(t)\|_{2}=\max \sqrt{y^{T}(t) y(t)} \leq \lambda_{0} .
$$

Then the asymptotic stability of system (6), with the output constraint (13), can be carried out by adding the LMIs (14) to (12), keeping $X=X^{T}>0$, as shown in $[16,17]$. Consider

$$
\begin{gathered}
{\left[\begin{array}{cc}
1 & x(0)^{T} \\
x(0) & X
\end{array}\right] \geq 0,} \\
{\left[\begin{array}{cc}
X & X C^{T} \\
C X & \lambda_{0}^{2} I
\end{array}\right] \geq 0 .}
\end{gathered}
$$

3.3. Leg Position Control of the Paraplegic Patient. The control of the knee paraplegic patient's position through functional electrical stimulation applied to the quadriceps muscle (see Section 2) is described in $[5,7]$. The state space equation is given by (6) with

$$
\begin{gathered}
A+\delta A=\left[\begin{array}{ccc}
0 & 1 & 0 \\
\tilde{f}_{21}\left(x_{1}\right) & -\frac{B}{J} & \frac{1}{J} \\
0 & 0 & -\frac{1}{\tau}
\end{array}\right], \\
B+\delta B=\left[\begin{array}{lll}
0 & 0 & \frac{G}{\tau}
\end{array}\right]^{T} .
\end{gathered}
$$

As described in Section 2, the function $\widetilde{f}_{21}\left(x_{1}(t)\right)$ is a nonlinearity of the system (see (2)) such that the range of parametric uncertainties is

$$
\tilde{f}_{21 \min } \leq \widetilde{f}_{21}\left(x_{1}(t)\right) \leq \tilde{f}_{21 \max } .
$$

In (2) the $x_{1}$ variable is at the denominator, and the analysis is more difficult when $x_{1}$ is equal to zero. In order to solve this inconvenience, Gaino, in [2], analytically expanded (2) in Taylor series of fifth order. Studying the expanded equation, in a closed interval of interest, Gaino, in [2], found that the approximation error becomes practically zero. The values found by Gaino, considering the operation point $\theta_{v 0}=$ $30^{\circ}$ and given the range of $-\pi / 6<\theta_{v}<\pi / 6$, are $\tilde{f}_{21 \max }=$ -21.7834 and $\tilde{f}_{21 \min }=-36.0086$.

The nominal plant is represented by matrices $A$ and $B$, given by

$$
\begin{gathered}
A=\left[\begin{array}{ccc}
0 & 1 & 0 \\
\tilde{f}_{0} & -\frac{B}{J} & \frac{1}{J} \\
0 & 0 & -\frac{1}{\tau}
\end{array}\right], \\
B=\left[\begin{array}{lll}
0 & 0 & \frac{G}{\tau}
\end{array}\right]^{T},
\end{gathered}
$$

where

$$
\tilde{f}_{0}=\frac{\tilde{f}_{21 \min }+\tilde{f}_{21 \max }}{2} .
$$

The matrices $\delta A$ and $\delta B$, in (6), are decomposed according to (7):

$$
\begin{gathered}
L=\left[\begin{array}{lll}
0 & \delta f_{\max } & 0
\end{array}\right]^{T}, \\
R_{A}=\left[\begin{array}{lll}
1 & 0 & 0
\end{array}\right], \\
\Delta=[\delta], \quad R_{B}=[0],
\end{gathered}
$$

where $-1 \leq \delta \leq 1$ and

$$
\delta f_{\max }=\frac{\tilde{f}_{21 \max }-\tilde{f}_{21 \min }}{2} .
$$



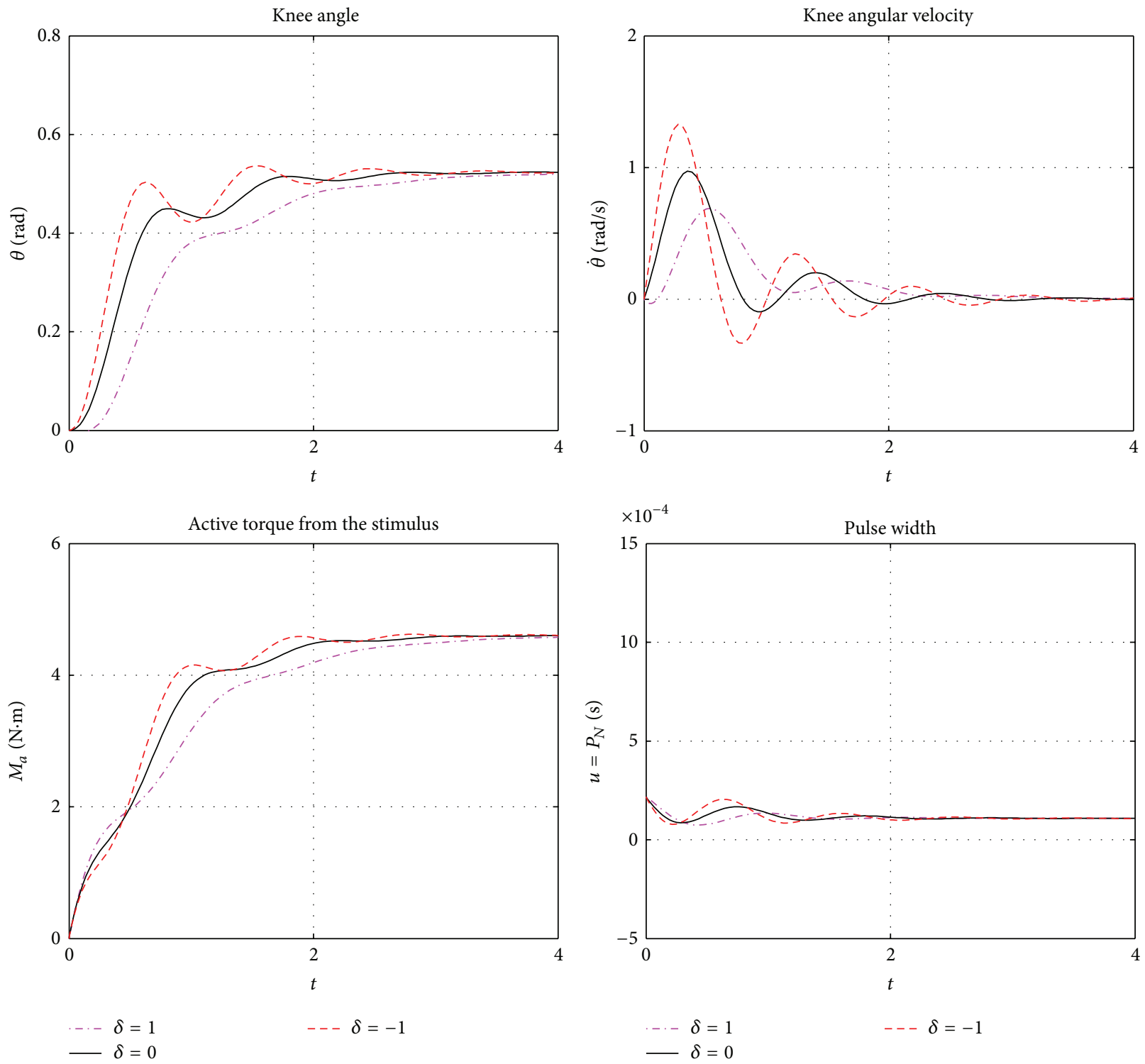

FIGURE 3: Simulation of the dynamic equation (10) of the paraplegic model for the operating point of $30^{\circ}, f_{21 \max }=-21.7834$ and $f_{21 \min }=$ -36.0086 , for $\delta=0, \delta=1$, and $\delta=-1$.

\section{Results}

4.1. Results without considering Output Constraints. Considering the parameters defined in $[5,7]$ (see Table 1 ) for $\theta_{0}=30^{\circ}$ and $-30^{\circ} \leq x_{1} \leq 30^{\circ}$, it follows that

$$
\begin{gathered}
x(0)=\left[\begin{array}{ccc}
-\theta_{v 0} & 0 & -M_{a 0}
\end{array}\right]^{T}=\left[\begin{array}{ccc}
-0.5236 & 0 & -4.6068
\end{array}\right]^{T}, \\
A=\left[\begin{array}{ccc}
0 & 1 & 0 \\
-28.8960 & -0.7459 & 2.7624 \\
0 & 0 & -1.0515
\end{array}\right], \\
B=\left[\begin{array}{lll}
0 & 0 & 44690
\end{array}\right]^{T}, \\
L=\left[\begin{array}{lll}
0 & 7.1126 & 0
\end{array}\right]^{T}, \\
C=\left[\begin{array}{lll}
1 & 0 & 0
\end{array}\right] .
\end{gathered}
$$

Applying the LMIs (11) and (12), using the software Matlab [18], for $\theta_{0}=30^{\circ}$, the state feedback matrix obtained was

$$
K=\left[\begin{array}{lll}
-0.3244 & 0.0999 & 0.0605
\end{array}\right] \times 10^{-3}
$$

and the constant $\epsilon$ was

$$
\epsilon=12.7728 \text {. }
$$

In Figure 3, the outputs of dynamic equation's simulations show that the graphics of the knee angles start at $0^{\circ}$, corresponding to $\Delta x_{1}=\theta_{\nu 0}=\pi / 6=-0.5236(\mathrm{rad})$. The graphics of the angular velocity of the knee start up at $0(\mathrm{rad} / \mathrm{s})$. Finally, the graphics of the active torques produced by the stimuli are initiated at $0(\mathrm{~N} \cdot \mathrm{m})$ corresponding to $\Delta x_{3}=$ $M_{a 0}=4.6068$ (see Section 2). Besides, the transient response of the dynamic compensator simulation applied to the 
TABLe 2: Poles of closed loop (10) for $\theta_{0}=30^{\circ}$, for $\delta=0, \delta=1$, and $\delta=-1$.

\begin{tabular}{lcc}
\hline$\delta=0$ & $\delta=1$ & $\delta=-1$ \\
\hline$-1.3777 \pm j 6.1086$ & $-1.6143 \pm j 5.4951$ & $-1.2186 \pm j 6.6799$ \\
-1.7463 & -1.2732 & -2.0646 \\
\hline
\end{tabular}

dynamic of the paraplegic patient, with $f_{21 \max }=-21.7834$, $f_{21 \text { min }}=-36.0086$, and the initial state is shown. Cases can be studied with other operation points, as shown in $[2,11]$, where a linearization result was considered for each operation point: $\pi / 4(\mathrm{rad})$ and $\pi / 3(\mathrm{rad})$.

The closed loop poles of system (10) are given in Table 2. In the first column of the table there are closed loop poles of the nominal system and in this case $\delta=0$. In the other two columns of the table there are closed loop poles considering the extreme values of the $\tilde{f}_{21}\left(x_{1}\right)$, respectively, for $\delta=1$ and $\delta=-1$. In all table columns it is possible to verify that the real parts of the poles are negative, which means that they are positioned in the left upper half-plane of the s-plane.

In Figure 3, the knee angle graphic for $\delta=0$, the curve stabilizes at $\pi / 6=0.52$ ( rad) in a time of about $3.5(\mathrm{~s})$. The graphic of active torque produced by the electric stimulus shows that the curve stabilizes at the mark of $4.6(\mathrm{~N} \cdot \mathrm{m})$ at 3.1 (s). The graph of the angular velocity of the knee stabilizes in the mark of $0(\mathrm{rad} / \mathrm{s})$ at $3.2(\mathrm{~s})$. The pulse width graphic stabilizes in $1.07 \times 10^{-4}$ at about $2.0(\mathrm{~s})$.

4.2. Results considering Output Constraints. In the second simulation, applying the LMIs (11), (12), and (14), with $\lambda_{0}=$ 6.8018 , using the software Matlab [18], for $\theta_{0}=30^{\circ}$, the state feedback matrix obtained was

$$
K=\left[\begin{array}{lll}
-0.2639 & 0.0602 & 0.0305
\end{array}\right] \times 10^{-3}
$$

and the constant $\epsilon$ was

$$
\epsilon=4.2263 \text {. }
$$

The closed loop poles of the system are given in Table 3 . In the first column of the table there are the closed loop poles of the nominal system and in this case $\delta=0$. In the other two columns of the table there are the closed loop poles considering the extreme values of the $\tilde{f}_{21}\left(x_{1}\right)$, respectively, for $\delta=1$ and $\delta=-1$. In all table columns it is possible to verify that the real parts of the poles are negative, which means that they are positioned in the left upper half-plane of the s-plane.

In Figure 4, the knee angle graphic for $\delta=0$, the curve stabilizes at $\pi / 6=0.52$ ( rad) in a time of about 4.0 (s). The graphic of active torque produced by the electric stimulus shows that the curve stabilizes at the mark of $4.6(\mathrm{~N} \cdot \mathrm{m})$ at 4.0 (s). The graph of the angular velocity of the knee stabilizes in the mark of $0(\mathrm{rad} / \mathrm{s})$ at $4.0(\mathrm{~s})$. The pulse width graphic stabilizes in $1.07 \times 10^{-4}$ at about 2.7 (s).

In both designs, no decay rate was specified.

Equation (5) shows that it is necessary that the pulse width satisfies $P_{N}>-M_{a 0} / G$. Actually, any value of $P_{N}$ greater than the ratio $-M_{a 0} / G$ satisfies the requirement. However, the previous relation implies that $P_{N}$ between $-M_{a 0} / G$ and $M_{a 0} / G$ satisfies the requirement (see Figure 4).
TABLE 3: Poles of closed loop (10) for $\theta_{0}=30^{\circ}, \lambda_{0}=6.8018$, for $\delta=0, \delta=1$, and $\delta=-1$.

\begin{tabular}{lcc}
\hline$\delta=0$ & $\delta=1$ & $\delta=-1$ \\
\hline$-1.0627 \pm j 5.8995$ & $-1.2390 \pm j 5.2721$ & $-0.9457 \pm j 6.4770$ \\
-1.0343 & -0.6818 & -1.2681 \\
\hline
\end{tabular}

\section{Discussions}

As can be seen, the plant input is the functional electrical stimulation pulse applied on the quadriceps muscle. The plant output is the movement of the leg of the paraplegic patient until an angle allowed by the conditions of the patient. So the initial objective was achieved: a state feedback matrix, $K$, was obtained considering norm-bounded uncertainties, such that the system in question becomes stable. The designed controller is able to make the patient's leg move from the rest to a desired angle and once the stimulation of the controller is removed, the leg goes back to the rest situation by gravity.

It was proved that Theorem 1 ensures stability for the open-loop system, while Theorem 2 ensures the asymptotic stability for the closed loop system. This fact can be confirmed by the analysis of Table 3 where it can be seen that the poles of the plant for different operating points have negative real parts, which means that they are positioned in the upper left half-plane of the s-plane.

Along with the study of the stability, graphical results could have been generated to control the speed of transient response, specifying a decay rate. It allows a shorter time recovery, as shown in [2].

As it is clear, a negative pulse width is impractical. Then restrictions must be imposed on input, as shown in Figure 5, to prevent the pulse width from reaching zero or negative values. According to Gaino in [2] with an appropriate combination of the decay rate and the upper limiting value for the variation of pulse width one can achieve the increasing or the decreasing of the control law amplitude.

The resulting simulation outputs shown in Figure 4 are identical to that obtained by Gaino in [2] in the same conditions. Here the simulation results were obtained using a restriction imposed on the output by a factor $\lambda_{0}=6.8018$, as it can be verified in Table 3 . As a consequence, the oscillation was eliminated from the pulse width curve, stabilizing in values of $P_{N}$ very close to one another in both simulations.

As mentioned by Sanches et al. in [8] "An electric current with a balanced, biphasic, rectangular waveform with a pulse width of $220 \mu \mathrm{s}$ was applied to the skin surface of the volunteer. The signal amplitude was then held constant for 3 seconds and considered a "step pattern" [5]. The pulse amplitude was adjusted to obtain an incomplete knee extension, reaching a maximum angle of $70^{\circ}$ with respect to the initial rest position. The frequency of the signal was $50 \mathrm{~Hz}$ [5]. For healthy persons, currents with amplitudes in the range of 60$80 \mathrm{~mA}$ are usually used, but in paraplegic patients, currents can reach $120 \mathrm{~mA}$." As mentioned by Ferrarin and Pedotti in [5], "In this way the presence of nonlinearity due to the muscle recruitment threshold and knee joint end stop could 

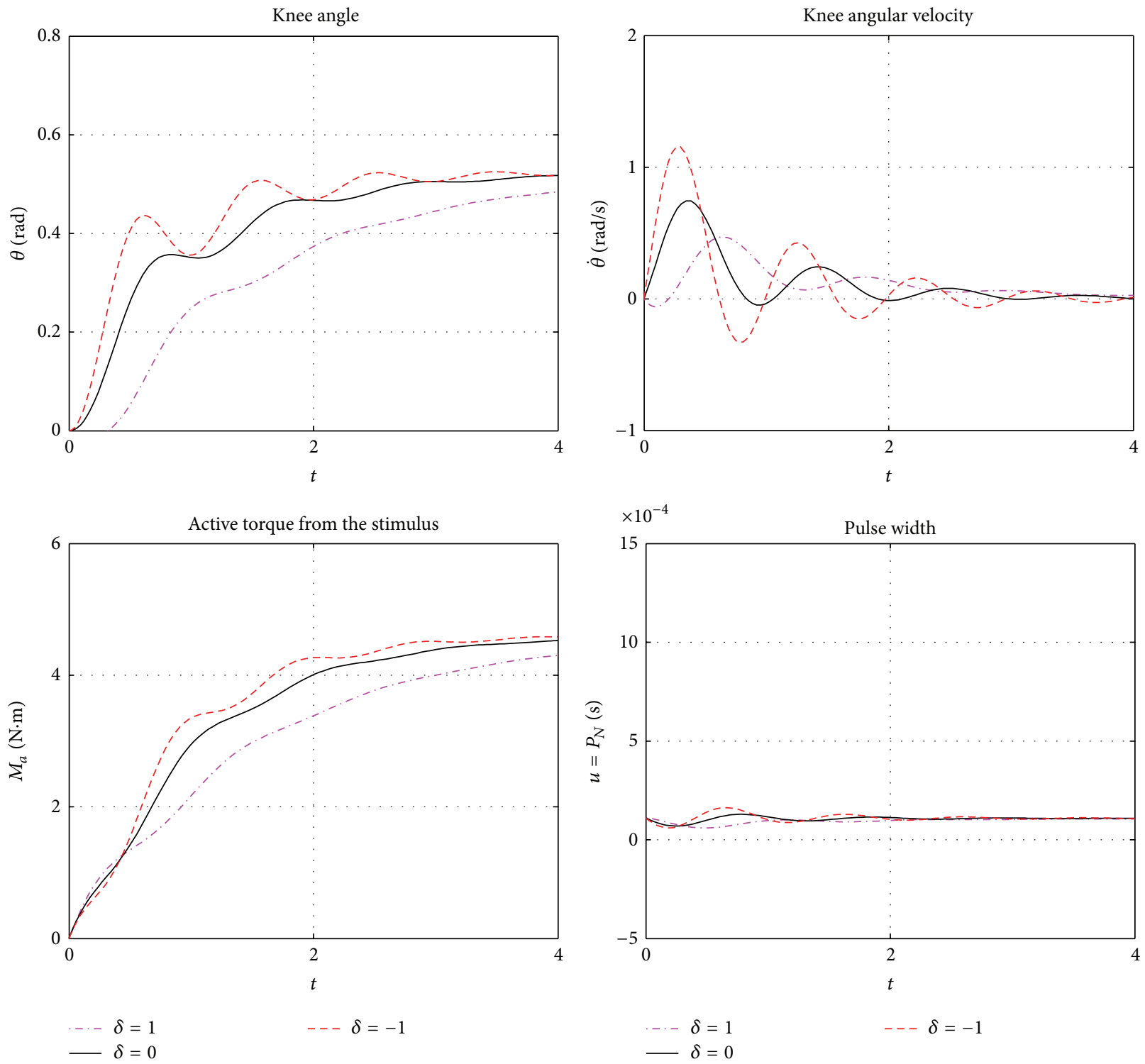

FigURE 4: Simulation of the dynamic equation (10) of the paraplegic model for the operating point of $30^{\circ}, f_{21 \max }=-21.7834$ and $f_{21 \min }=$ -36.0086 , using bounded output by the factor $\lambda_{0}=6.8018$, for $\delta=0, \delta=1$, and $\delta=-1$.

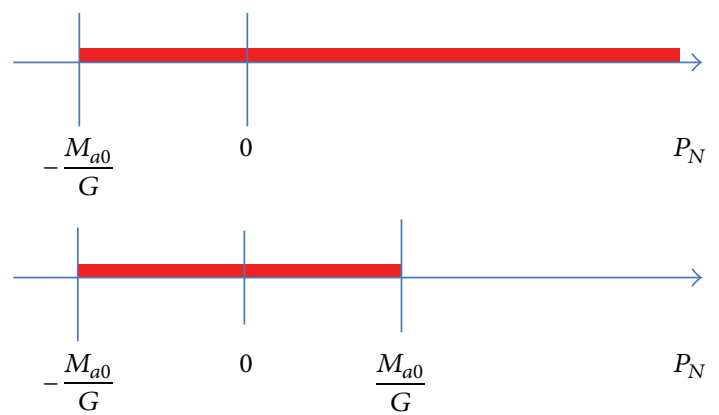

FIGURE 5: Range restriction for the pulse width.

be excluded." It is less dangerous to apply step patterns than sinusoidal wave forms.

\section{Conclusions}

The initial objective was achieved since a state feedback matrix, $K$, considering norm-bounded uncertainties, was obtained such that the system in question became stable. The designed controller is able to make the patient's leg move from the rest to a desired angle and once the stimulation is removed, the leg goes back to the rest situation by gravity.

It was proved that Theorem 1 ensures stability for the open-loop system, while Theorem 2 ensures the asymptotic stability for the closed loop system. The simulations of Section 4 show that the curves for the cases where $\delta=0$ are situated between the curves corresponding to the extremes values of $\delta$, that is, $\delta=1$ and $\delta=-1$, as it was expected. Table 3 shows that, for all values of $\delta$, the real parts of the poles are negative, and this indicates that the controller designed is able to maintain the stability of the plant. 


\section{Conflict of Interests}

The authors declare that there is no conflict of interests regarding the publication of this paper.

\section{Acknowledgments}

The authors gratefully acknowledge the Brazilian agencies CAPES, CNPq, and FAPESP, for the financial support.

\section{References}

[1] R. L. Lieber, P. D. Silva, and D. M. Daniel, "Equal effectiveness of electrical and volitional strength training for quadriceps femoris muscles after anterior cruciate ligament surgery," Journal of Orthopaedic Research, vol. 14, no. 1, pp. 131-138, 1996.

[2] R. Gaino, Controle de movimentos de pacientes paraplégicos utilizando modelos Fuzzy T-S, Tese (Doutorado)_Programa de Pós-Gradua ção em Engenharia Elétrica, Universidade Estadual Paulista "Júlio de Mesquita Filho", Ilha Solteira, São Paulo, Brazil, 2009, (Portuguese).

[3] H. E. Makssoud, D. Guiraud, and P. Poignet, "Mathematical muscle model for functional electrical stimulation control strategies," in Proceedings of the IEEE International Conference on Robotics and Automation, vol. 2, pp. 1282-1287, New Orleans, La, USA, 2004.

[4] S. J. Dorgan and M. J. O'Malley, "A mathematical model for skeletal muscle activated by N-let pulse trains," IEEE Transactions on Rehabilitation Engineering, vol. 6, no. 3, pp. 286-299, 1998.

[5] M. Ferrarin and A. Pedotti, "The relationship between electrical stimulus and joint torque: a dynamic model," IEEE Transactions on Rehabilitation Engineering, vol. 8, no. 3, pp. 342-352, 2000.

[6] R. Gaino, M. C. M. Teixeira, A. A. de Carvalho et al., "Realimentação derivativa e modelo fuzzy Takagi-Sugeno para controle da articulação do joelho de pacientes paraplégicos com o uso de acelerômetros," Brazilian Journal of Biomedical Engineering, vol. 27, no. 2, pp. 67-78, 2011 (Portuguese).

[7] M. C. M. Teixeira, G. S. Deaecto, R. Gaino, E. Assunção, A. A. de Carvalho, and U. C. Farias, "Design of a fuzzy Takagi-Sugeno controller to vary the joint knee angle of paraplegic patients," in Neural Information Processing, vol. 4234 of Lecture Notes in Computer Science, pp. 118-126, Springer, Berlin, Germany, 2006.

[8] M. A. A. Sanches, R. Gaino, R. F. Kozan et al., "Digital controllers desing considering hardware constraints: application in a paraplegic patient," Brazilian Journal of Biomedical Engineering, vol. 30, no. 3, pp. 232-241, 2014.

[9] J. Cao, "Improved delay-dependent stability conditions for MIMO networked control systems with nonlinear perturbations," The Scientific World Journal, vol. 2014, Article ID 196927, 4 pages, 2014.

[10] B. J. Rosa Filho, "Biomecânica Global," 2013, http://www.wgate.com.br/conteudo/medicinaesaude/fisioterapia/biomecanica .htm.

[11] D. N. T. P. Diogo, L. H. R. Bueno, M. R. Covacic, and R. Gaino, "Modelo Fuzzy Takagi-Sugeno para controle do ângulo de articulação do joelho de pacientes paraplégicos," Semina: Ciências Exatas e Tecnológicas, vol. 32, no. 2, pp. 215-228, 2012 (Portuguese).

[12] R. Gaino, M. C. M. Teixeira, R. Cardim, A. A. de Carvalho, E. Assunção, and M. A. A. Sanches, "Controle nãolinear Takagi-Sugeno do movimento de paraplégicos utilizando acelerômetros," in XXI Congresso Brasileiro de Engenharia Biomédica, pp. 1254-1257, CBEB, Salvador, Brazil, (Portuguese).

[13] R. Lu, W. Du, J. Wang, and A. Xue, "Robust $H_{2}$ control for descriptor system based on new bounded real lemma," Circuits, Systems, and Signal Processing, vol. 28, no. 6, pp. 869-882, 2009.

[14] S. P. Boyd, L. El-Ghaoui, E. Feron, and V. Balakrishnan, Linear Matrix Inequalities in System and Control Theory, Society for Industrial and Applied Mathematics, Philadelphia, Pa, USA, 1994.

[15] S. Boyd and L. Vandenberghe, Convex Optimization, Cambridge University Press, Cambridge, New York, NY, 7th edition, 2009.

[16] M. R. Covacic, M. C. M. Teixeira, E. Assunção, and R. Gaino, "LMI-based algorithm for strictly positive real systems with static output feedback," Systems \& Control Letters, vol. 61, no. 4, pp. 521-527, 2012.

[17] L. A. V. R. Filho, Filtragem Ótima Robusta em Sistemas Dinâmicos [Dissertação de Mestrado], Faculdade de Engenharia Elétrica e Engenharia de Computação, Universidade Estadual de Campinas, São Paulo, Brazil, 2004, (Portuguese).

[18] P. Gahinet, A. Nemirovski, A. J. Laub, and M. Chilali, LMI Control Toolbox User's Guide, The Mathworks Inc., Natick, Mass, USA, 1995. 


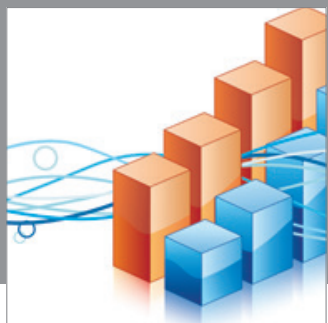

Advances in

Operations Research

mansans

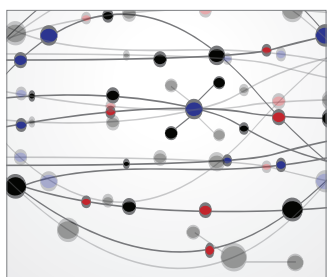

The Scientific World Journal
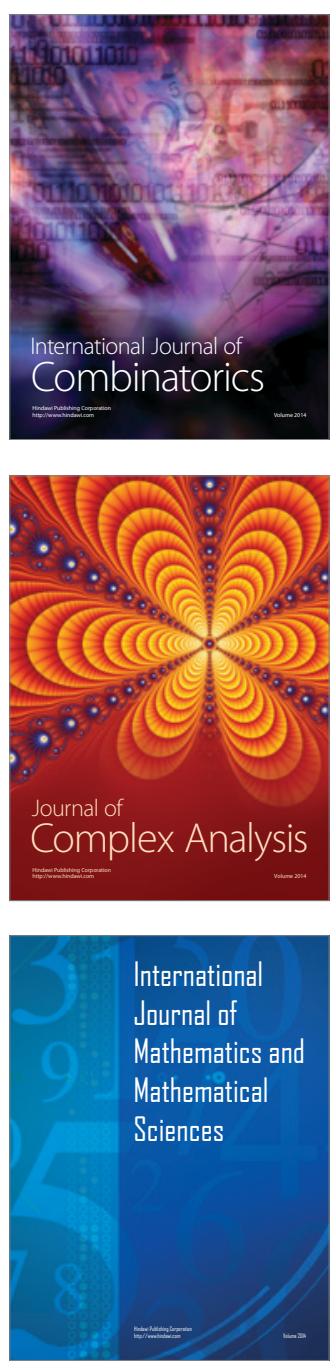
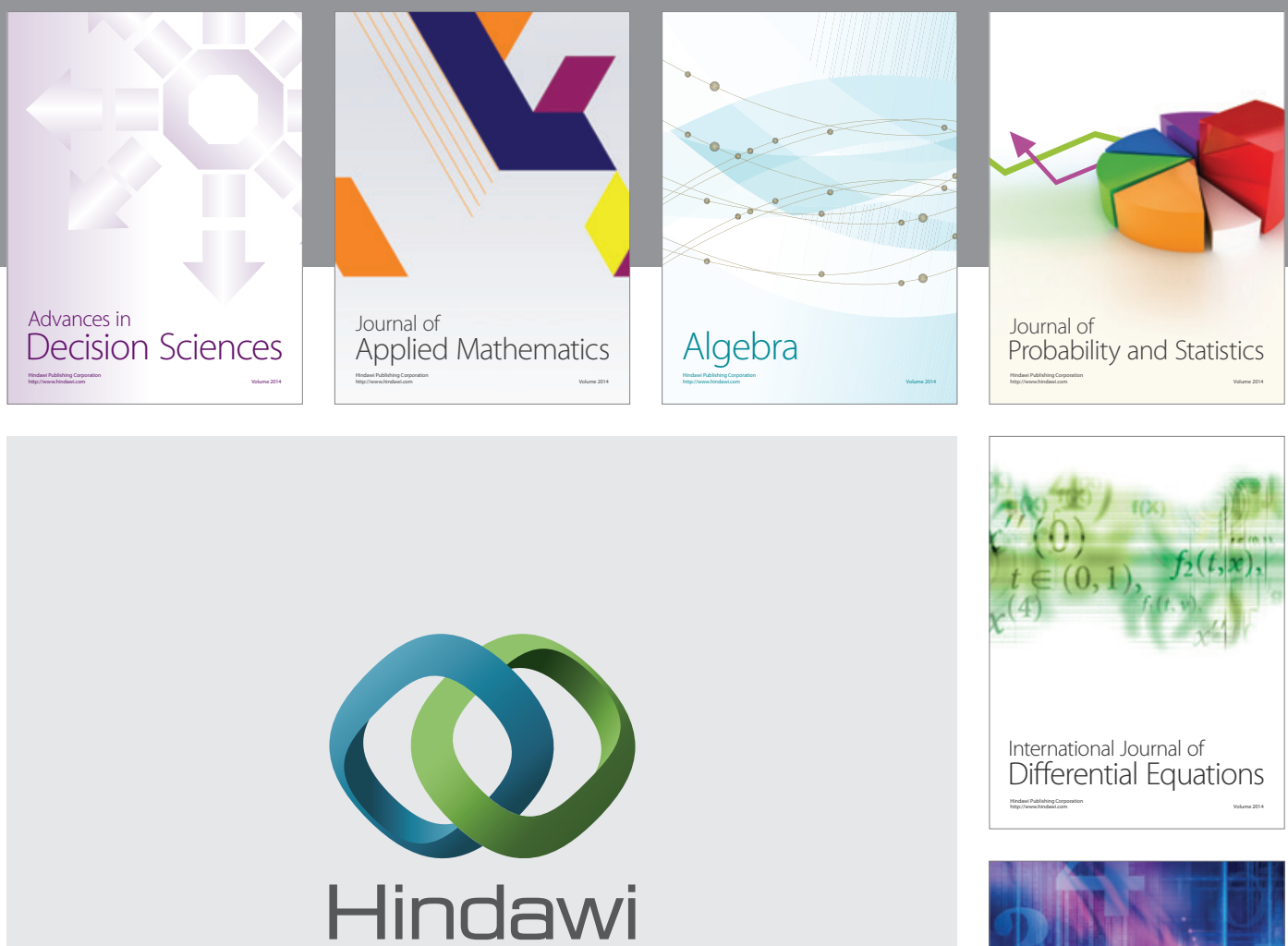

Submit your manuscripts at http://www.hindawi.com
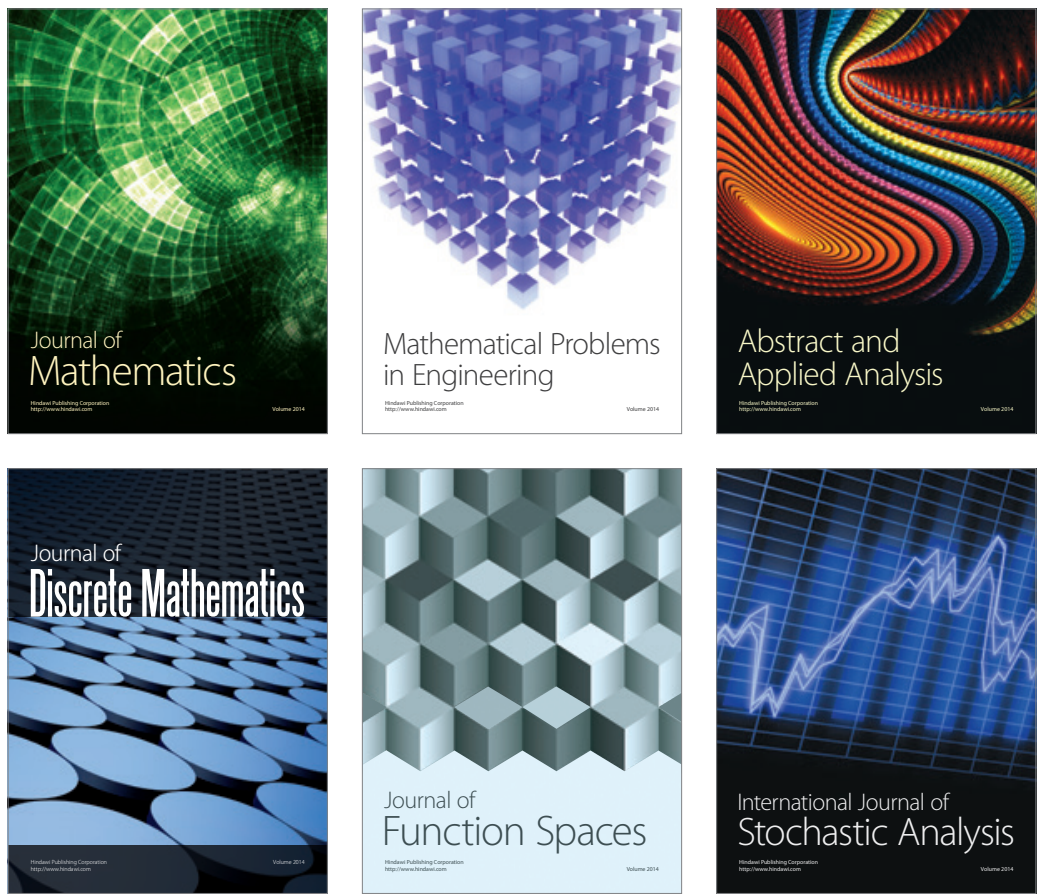

Journal of

Function Spaces

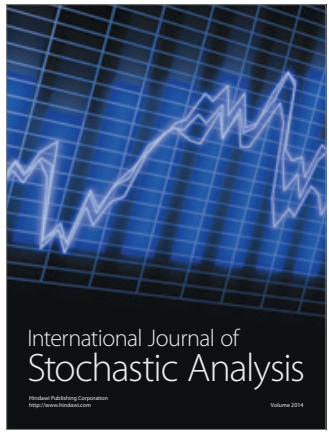

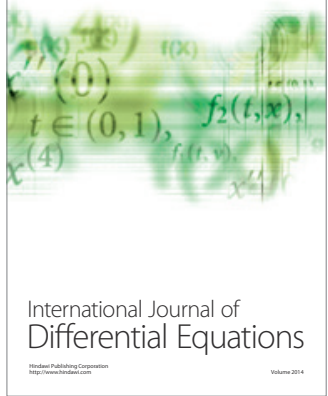
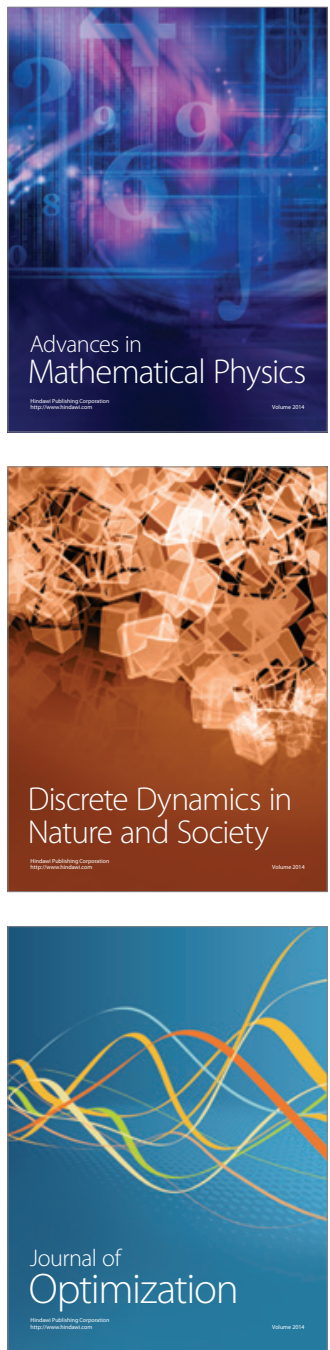